\title{
The utility of screening for perinatal depression in the second trimester among Chinese: a three-wave prospective longitudinal study
}

\author{
Ying Lau • Daniel Fu Keung Wong $\cdot$ Kin Sin Chan
}

Received: 3 August 2009 / Accepted: 29 November 2009 /Published online: 8 January 2010

(C) Springer-Verlag 2009

\begin{abstract}
This paper aims to study the pattern of perinatal depressive symptomatology and determine the predictive power of second trimester perinatal depressive symptoms for future perinatal periods. A population-based sample of 2,178 women completed the Edinburgh Postnatal Depression Scale (EPDS) in the second and third trimesters and at 6 weeks postpartum. Repeated measures ANOVAs were used to determine the EPDS scores across three stages. The predictive power of the second trimester EPDS score in identifying women with an elevated EPDS score in the third trimester and at 6 weeks postpartum were determined. The predictive power of the second trimester EPDS score was further assessed using stepwise logistic regression and receiver operator characteristic curves. EPDS scores differed significantly across three stages. The rates were $9.9 \%$, $7.8 \%$, and $8.7 \%$ for an EPDS score of $>14$ in the second and third trimesters and at 6 weeks postpartum, respectively.
\end{abstract}

\footnotetext{
Y. Lau

School of Health Sciences, Macao Polytechnic Institute,

Macau, China

D. F. K. Wong

Department of Social Work and Social Administration, University of Hong Kong,

Hong Kong, China

\section{K. S. Chan}

Faculty of Social Sciences and Humanities,

The University of Macau,

Macau Special Administration Region (SAR), China

Y. Lau $(\bowtie)$

5/F Centro Hotline Building,

No. 335-341, Alameda Dr. Carlos D’ Assumpcao,

Macau, China

e-mail: ylau@ipm.edu.mo
}

Using a cut-off of $14 / 15$, the second trimester EPDS score accurately classified $89.6 \%$ of women in the third trimester and $87.2 \%$ of those at 6 weeks postpartum with or without perinatal depressive symptomatology. Women with a second trimester EPDS score $>14$ were 11.78 times more likely in the third trimester and 7.15 times more likely at 6 weeks postpartum to exhibit perinatal depressive symptomatology after adjustment of sociodemographic variables. The area under the curve for perinatal depressive symptomatology was 0.85 in the third trimester and 0.77 at 6 weeks postpartum. To identify women at high risk for postpartum depression, healthcare professionals could consider screening all pregnant women in the second trimester so that secondary preventive intervention may be implemented.

Keywords Perinatal depressive symptoms. Predictive power Chinese

\section{Introduction}

Perinatal depression is increasingly a target of improved awareness, clinical research, and public health efforts, yet remains a serious health concern for both pregnant and postpartum women (Dossett 2008). It has far-reaching consequences, affecting not only the women but also their children and relationships. Many consequences can arise among affected women, including poor prenatal care (Kim et al. 2006), increased social stress (Flynn et al. 2007), and poor quality of life (Orr et al. 2007). Consequences for infants range from immediate risks, such as preterm delivery (Suri et al. 2007), lower birth weight (Evans et al. 2007), and neonatal complications (Alder et al. 2007), to longer term sequelae, such as impaired neurological, cognitive, emotional, and social development (Milgrom et al. 2004; 
Talge et al. 2007). In addition, mothers with depressive symptoms have been found to have more complex behavioral interactions with their children, to be less responsive and sensitive, and to be more intrusive in their interactions, and their children are more likely to develop an insecure attachment to their mother at 36 months (Campbell et al. 2004).

The identification of perinatal depression is considered a critical goal of the maternal care system (Buist et al. 2005), but only a minority of women suffering from perinatal depression are identified by healthcare providers of either maternal or infant care (Thio et al. 2006). High resource utilization and the costs associated with clinician diagnoses using diagnostic questionnaires have resulted in the development of lay-administered instruments and patient self-report questionnaires to identify and quantify depression in obstetric populations (Boyd et al. 2002). A selfreport questionnaire is not diagnostic; however, it is sensitive to depressive symptoms (Bennett et al. 2004). Cut-off scores are designed to detect respondents who are likely to be diagnosed with depression (Sharp and Lipsky 2002). Because the prevention of perinatal depression is not reliable, early detection is the best approach. Screening all women is logical, because no woman can be considered risk free (Dossett 2008). The Edinburgh Postnatal Depression Scale (EPDS) is a widely used first step in identifying perinatal depression (Boyd et al. 2005), and generally takes 5 min to complete depending on the level of literacy of the woman. Research suggests that women who experience perinatal depressive symptoms use more healthcare resources during pregnancy than do women who are not depressed, which potentially affords providers greater opportunity to screen for and address depressive symptoms during the antenatal period (Andersson et al. 2004).

Empirical evidence found that comparatively lower cutoff value of perinatal depressive symptomatology among Asian women (Lee et al 1998; Wong et al. 2009) compared to western women (Felice et al. 2006; Adouard et al. 2005). The degree of heterogeneity may also suggest that various women with different cultural attitudes to feeling and expressing distress among different cultural groups (Gibson et al. 2009). This difference might be a reflection of Asian women continues to follow traditional character of selfrestraint under the influence of Confucianism (Shih 1996). It focused on interpersonal relationships and social obligations, Asian people are required to practice self-restraint and exhibit prudence, benevolence, and righteousness. Therefore, they might be reluctance to show their emotion. As a result, adopting the cut-off score of western version of screening tool for the Asian population will yield an unsatisfactorily high rate of false negatives. This illustrates the importance of more investigation of a psychiatric rating instrument in the different cultural settings.
Some studies have found that levels and rates of depression are similar in pregnancy and the postpartum period (Bowen and Muhajarine 2006; Figueiredo et al. 2007), whereas others suggest that depression may be more prevalent during pregnancy than the puerperium (Limlomwongse and Liabsuetrakul 2006; Bennett et al. 2008), and still others have found that the prevalence rates of perinatal depression are lower during pregnancy compared to the postpartum period (Gorman et al. 2004; Dietz et al. 2007). In addition, the levels and rates of the second and third trimesters have been found to differ significantly in previous studies (Evans et al. 2001; van Bussel et al. 2009). An understanding of the difference in perinatal depression during different perinatal periods is critical because not only could a number of contradictory findings (Figueiredo et al. 2007; Bennett et al. 2008) in the literature be clarified but also the focus of treatment likely needs to vary for these periods of depression.

For years, very little attention has been paid to the connection between antenatal and postnatal depressive symptomatology. However, more recently, both researchers and healthcare professionals have started to consider the possibility that a continuum exists. The strongest predictor of perinatal depression is a history of depression (Leigh and Milgrom 2008) and previous perinatal depression (Howell et al. 2006; Dietz et al. 2007). Scholars have found that among women with postpartum depression, over $50 \%$ had depression identified either before or during the pregnancy (Dietz et al. 2007). One study found that the profiles of antenatal and postnatal depressive symptoms were different (Kammerer et al. 2009), whereas other research showed that the psychosocial risk factors of antenatal depression were similar to those of postnatal depression (Lee and Chung 2007). The empirical results are contradictory, and the pattern of perinatal depression has yet to be elucidated.

It is important to note that the link between antenatal and postnatal depressive symptoms is based on assessments across the whole pregnancy process. Unfortunately, inconsistent findings (Bennett et al. 2008; Kim et al. 2008), small sample size (Jomeen and Martin 2008), and research conducted among select groups, such as low-income mothers (Diaz et al. 2007), have resulted in selection bias and poor external validity. In addition, the use of different instruments (Gorman et al. 2004; Bennett et al. 2008), various cut-off points (Bennett et al. 2008; Kim et al. 2008) with heterogeneous sensitivity and specificity (Gibson et al. 2009), and inconsistent screening procedures (Bennett et al. 2008; Kim et al. 2008) prevent direct comparison across studies. A comprehensive review of the literature showed that the reported figures vary among and even within countries, from $0.5 \%$ to over $60 \%$ (Lee and Chung 2007). To our knowledge, few studies have specifically assessed the pattern of perinatal depression or the concordance among EPDS scores in the second and third trimesters and 
at 6 weeks postpartum among Chinese women. The objective of the present study was to determine the pattern of perinatal depressive symptomatology in the second trimester and to evaluate the predictive power of the second trimester EPDS score for depressive symptomatology in the third trimester and at 6 weeks postpartum.

\section{Methods}

\section{Design and sample}

The study reported here employed a three-wave prospective longitudinal design. Longitudinal research serves two primary purposes: to describe patterns of change and to establish the direction and magnitude of causal relationships (Menard 2002). The target population was Hong Kong Chinese women. The systematic sampling method was adopted to enhance the representativeness of the sample (Rubbin and Babbie 2001) and allow for better generalizability of the findings. It is estimated that 123,069 women attended the targeted antenatal outpatient clinics between 2003 and 2004 (12 months; Hospital Authority 2004). We aimed to draw a sample of 2,000 women from the approximately 120,000 pregnant women in the six target hospitals over a period of 1 year. Dividing 120,000 by 2,000 , we obtained a sampling interval of 60 and, starting with the random number 19 , selected every 60 th woman thereafter. The sample thus consists of cases numbered 19, 79, 139, 199...120,019 (Singleton and Straits 1999). The women who were served by the six major hospitals under the Hospital Authority were considered to be a representative sample of pregnant women in the general population because they were drawn from a group that covered four different clusters in three major areas in Hong Kong (Hospital Authority 2004). Assuming a true prevalence of $10 \%$, as estimated in a previous Hong Kong study (Chung et al. 2001), approximately 2,000 participants were required (Cohen 1988) to gain a 95\% confidence interval for the study estimates with a width of $\pm 2 \%$. The exclusion criteria were: (1) carrying an abnormal baby and (2) being a nonChinese woman. The inclusion criteria were: (1) primiparas or multiparas and (2) undergoing either a vaginal or instrumental delivery in one of the six hospitals.

\section{Measurement}

A Chinese version of a self-administered questionnaire was used to collect sociodemographic data, which included age, educational level, duration of stay in Hong Kong, marital status, employment, monthly income (HK\$5,000 was the cut-off because this is less than half the median monthly domestic household income in Hong Kong; Hong Kong
Census and Statistics Department 2007), size of residence ( $300 \mathrm{ft}^{2}$ was the cut-off because this is below the average living space per household in Hong Kong; Hong Kong Census and Statistics Department 2007; Hong Kong Housing Authority 2007), and family composition. Based on a review of the literature (Lee and Chung 2007; Dossett 2008), all of these are potential confounders of the association between the independent variables and perinatal depressive symptomatology.

The EPDS (Cox et al. 1987) was used to screen for perinatal depressive symptoms because it has already been validated in the antenatal (Felice et al. 2006) and postnatal periods (Buist et al. 2006). The EPDS is a 10-item selfrating instrument, with each item scored on a 4-point scale. The minimum and maximum total scores are 0 and 30 , respectively. This scale focuses on the cognitive and affective features of depression. A Chinese version of the EPDS that has been tested in Hong Kong and demonstrated good reliability and validity was used (Lee et al. 1998). The EPDS scores are divided into three levels: 0-9, insignificant; $>9$, mild to severe depressive symptoms; and $>14$, severe depressive symptoms (Lee et al. 2004a). Published data show that different EPDS cut-off points are used for the different stages of pregnancy (Su et al. 2007). However, a higher cut-off of $>14$ is recommended antenatally, which gives a reported $100 \%$ sensitivity and $96 \%$ specificity for identifying women with clinical major depression (Murray and Cox 1990; Mattney et al. 2006). The prevalence of major depression in the validation study was $7 \%$, and the positive predictive value (which is strongly influenced by prevalence) of the EPDS was approximately $65 \%$. Therefore, cut-off scores of $9 / 10$ and $14 / 15$ were used in this study. The Cronbach's $\alpha$ coefficient of the EPDS was 0.81 to 0.87 , which suggests good internal consistency.

\section{Data collection}

Ethical approval that complied with the Declaration of Helsinki was obtained in December 2004 from the Institutional Review Boards of the six hospitals involved (from four clusters in the Hong Kong Hospital Authority). All of the women who attended the target antenatal clinics within the data collection period of December 2004 to December 2006 were screened and followed-up. Those who were eligible were systematically selected and invited to participate in the study on a voluntary basis, and their informed consent was obtained. The women were asked to complete the questionnaire themselves and were assured of confidentiality. The first set of data was collected at approximately 18 weeks of gestation (the mean week of the second trimester), and the second at about 32 weeks (the mean week of the third trimester) during routine antenatal follow-up. The final survey, which was carried 
out 6 weeks after delivery, was achieved via postal return. A telephone reminder was used to maximize returns. The 6-week postpartum check is an ideal time for screening because this is the most vulnerable time in the postpartum period (Lee and Chung 2007; Dossett 2008). Women with elevated EPDS scores, those acknowledging thoughts of self-harm, and those about whom healthcare professionals had concerns were encouraged and assisted to access appropriate referral pathways.

Data analysis

The SPSS 16.0 statistical software package was used for the statistical analysis. Descriptive analysis of the sociodemographic data was carried out. A reliability test was carried out for the EPDS in the three stages. Pearson's productmoment correlations were used to examine the relationships among the EPDS scores. A repeated measure of analysis was used to analyze the changes of EPDS scores across three stages. The analysis was reported as multivariate results of the repeated measures of analysis of variances (ANOVAs). In multivariate results, Wilks' Lambda is historically the most widely used test to show the significant results (Munro 2005) by using the generalized linear model procedure of SPSS. The concordance in EPDS scores

Fig. 1 Flowchart for the implementation of the study across time was evaluated using the McNemar Exact Test. Predictive values were calculated using the second trimester EPDS score. The null hypothesis for this test stated that maternal EPDS scores were independent, and rejected whenever the $p$ value was lowered than 0.05 . The predictive performance of the second trimester EPDS score was determined using stepwise logistic regression and the receiver operating characteristic (ROC) curves. The recommended cut-off scores of $9 / 10$ for mild to severe depressive symptoms and 14/15 for severe depressive symptomatology (Lee et al. 2004b; Mattney et al. 2006) were used for all calculations.

\section{Results}

A total of 2,365 Hong Kong Chinese women in six hospitals were invited to join the study (Fig. 1), of whom 2,178 completed the questionnaires in the first stage (response rate $=92.1 \%$ ). One hundred and eighty-seven women $(7.9 \%)$ refused to participate. The primary reasons for refusal were lack of time, fatigue, and reluctance to disclose information. The demographic characteristics of the women who refused and those who participated were not significantly different $(p>0.05)$. The retention of women through the 3 -month assessment period was 1,569 , with

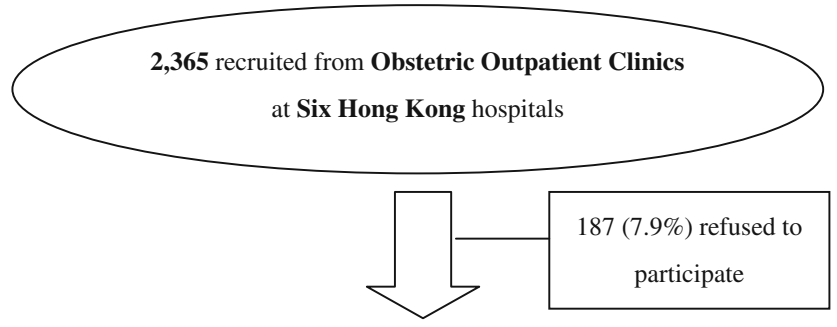

$\mathbf{2 , 1 7 8}(\mathbf{9 2 . 1 \%})$ finished THE FIRST SET OF QUESTIONNAIRES

(Socio-demographic characteristics and EPDS1) at the antenatal clinics $2^{\text {nd }}$ Trimester

(12-24 weeks gestations)

Time 2:

3rd Trimester

(>24-36 week gestations)

Time 3:

(6 weeks after

delivery)

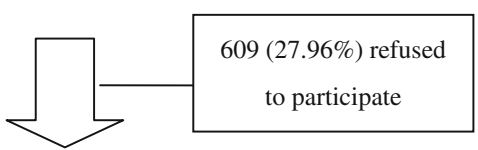

1,569 (72.0\%) completed THE SECOND SET OF

QUESTIONNAIRES (EPDS2) at the antenatal clinics

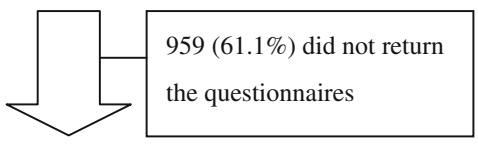

$610(38.9 \%)$ returned THE THIRD SET OF QUESTIONNAIRES

(EPDS3) by mail 
$72.0 \%$ completing the questionnaires in the second stage. The reason that the women withdrew from the study at this time was either that they had transferred their antenatal follow-up assessments to the private sector or that they were too busy to engage in antenatal education programs. The third stage of data collection was conducted by post, and where possible the researchers made telephone calls to attempt to increase the number of returns (Miller 1991). The number of women retained throughout the entire 3-month assessment period was 610 , with $38.9 \%$ completing the questionnaire in the third stage. This response rate is similar to the typical response rate for mail surveys - between $20 \%$ and $40 \%$ (Nachmias and Nachmias 2004). The reason for withdrawal may have been the necessity to care for the baby in the postnatal period. The demographic characteristics of the three groups (the women who withdrew in the second stage, those who withdrew in the third stage, and those who did not withdraw) were not significantly different, according to the chi-square test $\left(X^{2} ; p>0.05\right)$, and the response rates of the groups that scored above and below the EPDS cut-offs at the three stages were similar.

Table 1 presents the sociodemographic characteristics of the participants in the three stages. The majority $(85.8 \%$ to $89.0 \%$ ) were older than 25 , had attained at least a secondary school level of education (94.4\% to $95.0 \%$ ), and had lived in Hong Kong for more than 1 year $(89.3 \%$ to $91.3 \%)$. Most of them were married ( $92.1 \%$ to $93.8 \%$ ), the majority $(77.2 \%$ to $77.5 \%)$ of whom for more than 1 year. More than half $(55.6 \%$ to $57.0 \%)$ of the women had full-time jobs with a total monthly family income $>\mathrm{HK} \$ 5,000(91.8 \%$ to $92.5 \%)$. More than half $(72.0 \%$ to $75.7 \%)$ lived in private houses $\geq 300 \mathrm{ft}^{2}(82.8 \%$ to $85.8 \%)$. Most of them did not have a parent or parent-in-law living in the same household.

\section{Pattern of perinatal depressive symptomatology}

The prevalence of severe depressive symptomatology $($ EPDS $>14)$ in the second and third trimesters and at 6 weeks postpartum was $9.9 \%, 7.8 \%$, and $8.7 \%$, respectively. The percentage of women with an EPDS score $>9$ was $36.5 \%(n=796)$ in the second trimester, decreasing to $32.0 \%(n=502)$ in the third trimester and $31.6 \%(n=193)$ at 6 weeks postpartum. The mean EPDS scores in the second and third trimesters and at 6 weeks postpartum were 8.29 $(\mathrm{SD}=4.69), 7.49(\mathrm{SD}=4.66)$, and $7.23(\mathrm{SD}=5.14)$, respectively. Repeated measures ANOVAs were used to determine the EPDS scores across three stages. EPDS scores differed significantly across three-assessment time $(p<0.001)$.

Predictive values

The predictive values of the second trimester EPDS score in identifying women in the third trimester and at 6 weeks after delivery with an elevated EPDS score and exhibiting perinatal depressive symptomatology were calculated (Jekel and Jekel 2007). In this study, positive predictive value refers to the proportion of women who screened positively in the second trimester, using the EPDS, who exhibited perinatal depressive symptomatology in the third trimester or at 6 weeks after delivery. The proportion of women who screened negatively in the second trimester, using the EPDS, who did not exhibit perinatal depressive symptomatology in the third trimester or at 6 weeks after delivery is termed the negative predictive value.

The predictive values of the second trimester score are presented in Table 2. The McNemar Exact Test for the second trimester EPDS score using various thresholds was significant at all times, which suggests consistency in perinatal depressive symptoms among the second, third trimesters, and at 6 weeks postpartum. The EPDS score in the second trimester was significantly correlated with that in the third trimester $(r=0.66, p<0.01)$ and at 6 weeks postpartum $(r=0.53, p<0.01)$; a strong relationship between maternal EPDS scores in the third trimester and at 6 weeks postpartum was also noted $(r=0.63, p<0.01)$.

Using the cut-off of $9 / 10$, the second trimester EPDS score accurately classified 1,214 (77.4\%) women in the third trimester and $429(70.3 \%)$ women at 6 weeks postpartum with or without mild or severe perinatal depressive symptomatology; however, it failed to identify 19 (15.4\%) women in the third trimester and $14(26.4 \%)$ women at 6 weeks postpartum who exhibited severe perinatal depressive symptomatology. In comparison, using the cut-off of $14 / 15$, the second trimester EPDS score accurately classified 1,406 (89.6\%) women in the third trimester and 532 $(87.2 \%)$ women at 6 weeks postpartum with or without severe depressive symptomatology; however, it failed to detect 65 women in the third trimester and 33 women at 6 weeks postpartum who exhibited severe postpartum depressive symptomatology.

\section{Univariate and multivariate analysis}

Based on the second trimester EPDS score, maternity probability to exhibit depression in the third trimester and at 6 weeks postpartum was calculated using stepwise logistic regression, as shown in Table 3 . Women with a second trimester EPDS score $>9$ were 9.94 times more likely in the third trimester $(95 \% \mathrm{CI}=7.78-12.69)$ and 4.42 times more likely at 6 weeks postpartum $(95 \% \mathrm{CI}=3.07$ 6.36) to exhibit minor to severe postpartum depressive symptomatology. Women with a second trimester EPDS score $>14$ were 12.27 times more likely in the third trimester $(95 \% \mathrm{CI}=8.15-18.48)$ and 6.90 times more likely at 6 weeks postpartum $(95 \% \mathrm{CI}=3.66-12.99)$ to exhibit major postpartum depressive symptomatology. After con- 
Table 1 Sociodemographic characteristics and Edinburgh Postnatal Depression Scale Scores of participants in three stages of this study

\begin{tabular}{|c|c|c|c|c|}
\hline \multicolumn{2}{|l|}{ Characteristics } & $\begin{array}{l}\text { Time } 1: 2 \text { nd trimester } \\
(n=2,178) \\
n(\%)\end{array}$ & $\begin{array}{l}\text { Time } 2: 3 \text { rd trimester } \\
(n=1,569) \\
n(\%)\end{array}$ & $\begin{array}{l}\text { Time } 3: 6 \text { weeks } \\
\text { after delivery }(n=610) \\
n(\%)\end{array}$ \\
\hline \multirow[t]{2}{*}{ Age } & $\leqq 25$ & $309(14.2)$ & $211(13.4)$ & $67(11.0)$ \\
\hline & $>26$ & $1,869(85.8)$ & $1,358(86.6)$ & $543(89.0)$ \\
\hline \multirow[t]{2}{*}{ Educational level } & $\leqq$ Primary & $121(5.6)$ & $79(5.0)$ & $32(5.2)$ \\
\hline & $>$ Primary & $2,057(94.4)$ & $1,490(95.0)$ & $578(94.8)$ \\
\hline \multirow[t]{2}{*}{ Duration in Hong Kong } & $\geq 1$ year & $1,982(91.0)$ & $1,433(91.3)$ & $548(89.8)$ \\
\hline & $<1$ year & $196(9.0)$ & $136(8.7)$ & $62(10.2)$ \\
\hline \multirow[t]{2}{*}{ Marital status } & Single/separated /divorced & $173(7.9)$ & $111(7.1)$ & $38(6.2)$ \\
\hline & Married/cohabited & $2,005(92.1)$ & $1,458(92.9)$ & $572(93.8)$ \\
\hline \multirow[t]{2}{*}{ Length of marriage } & $<1$ year & $490(22.5)$ & $358(22.8)$ & $138(22.6)$ \\
\hline & $\geq 1$ year & $1,688(77.5)$ & $1,211(77.2)$ & $472(77.4)$ \\
\hline \multirow[t]{2}{*}{ Employment of participant } & Part-time or unemployed & $966(44.4)$ & $683(43.5)$ & $262(43.0)$ \\
\hline & Full time & $1,212(55.6)$ & $886(56.5)$ & $348(57.0)$ \\
\hline \multirow[t]{2}{*}{ Total monthly family income $\mathrm{a}^{\mathrm{a}}$} & $<$ Hong Kong $\$ 5,000(\sim$ US\$641) & $178(8.2)$ & $118(7.5)$ & $46(7.5)$ \\
\hline & $\geq$ Hong Kong $\$ 5,000(\sim$ US\$641) & $2,000(91.8)$ & $1,451(92.5)$ & $564(92.5)$ \\
\hline \multirow[t]{2}{*}{ Types of residence } & Public housing & $529(24.3)$ & $391(24.9)$ & $171(28.0)$ \\
\hline & Private housing & $1,649(75.7)$ & $1,178(75.1)$ & $439(72.0)$ \\
\hline \multirow[t]{2}{*}{ Size of residence ${ }^{b}$} & $\geqq 300 \quad \mathrm{ft}^{2}$ & $1,868(85.8)$ & $1,346(85.8)$ & $505(82.8)$ \\
\hline & $<300 \mathrm{ft}^{2}$ & $310(14.2)$ & $223(14.2)$ & $105(17.2)$ \\
\hline \multirow[t]{2}{*}{ Live with parent-in-law } & Yes & $155(7.1)$ & $115(7.3)$ & $47(7.7)$ \\
\hline & No & 2,032 (92.9) & $1,454(92.7)$ & $563(92.3)$ \\
\hline \multirow[t]{2}{*}{ Live with parent } & Yes & $464(21.3)$ & $334(21.3)$ & $148(24.3)$ \\
\hline & No & $1,714(78.7)$ & $1,235(78.7)$ & $462(75.7)$ \\
\hline \multicolumn{5}{|c|}{ Edinburgh Postnatal Depression Scale Scores } \\
\hline EPDS $>9$ & & $795(36.5)$ & $502(32.0)$ & $193(31.6)$ \\
\hline \multirow[t]{2}{*}{ EPDS $>14$} & & $216(9.9)$ & $123(7.8)$ & $53(8.7)$ \\
\hline & & Mean \pm SD & Mean \pm SD & Mean \pm SD \\
\hline \multirow[t]{3}{*}{ EPDS score } & Wilks' Lambda ${ }^{\mathrm{c}}$ & $8.29 \pm 4.69$ & $7.49 \pm 4.66$ & $7.23 \pm 5.14$ \\
\hline & $F$ & 18.66 & & \\
\hline & Sig. & $<0.001$ & & \\
\hline
\end{tabular}

EPDS Edinburgh Postnatal Depression Scale, SD Standard Deviation

${ }^{a}$ Total monthly family income: Hong Kong $\$ 5,000$ is considered as a cut-off because this monthly income is below the half of the median monthly domestic household income in Hong Kong (Hong Kong Census and Statistics Department 2007)

${ }^{\mathrm{b}}$ Size of residence: $300 \mathrm{ft}^{2}$ is considered as a cut-off because this size of residence is below the average living space per household in Hong Kong (Hong Kong Census and Statistics Department 2007; Hong Kong Housing Authority 2007)

' Wilks' Lambda is a test (repeated measures of analysis of variances) for the differences of EPDS scores in three stages

trolling for sociodemographic variables, women with a second trimester EPDS score $>9$ were 9.74 times more likely in the third trimester $(95 \% \mathrm{CI}=7.59-12.51)$ and 4.38 times more likely at 6 weeks postpartum $(95 \% \mathrm{CI}=3.00$ 6.38) to exhibit minor to severe postpartum depressive symptomatology. Women with a second trimester EPDS score $>14$ were 11.78 times more likely in the third trimester $(95 \% \mathrm{CI}=7.12-18.01)$ and 7.15 times more likely at 6 weeks postpartum $(95 \% \mathrm{CI}=3.63-14.09)$ to exhibit major postpartum depressive symptomatology.
Receiver operator characteristics analysis

The ability of the second trimester EPDS score to accurately predict and discriminate between postpartum depressive and non-depressive cases was further evaluated using receiver operator characteristic curve analysis. An ROC curve is constructed by plotting the true-positive rate against the false-negative rate (i.e. one minus true-negative rate) over a range of cut-off scores (Fletcher and Fletcher 2005). In this study, the true-positive rate refers to the 
ability of the second trimester EPDS score to identify correctly all screened women classified with perinatal depressive symptomatology in the third trimester or at 6 weeks after delivery. The true-negative rate is the ability of the second trimester EPDS score to identify correctly all screened women not classified with perinatal depressive symptomatology in the third trimester or at 6 weeks after delivery. The overall accuracy of an instrument can be described as the area under the ROC curve. The larger is the area under the curve (AUC), the better is the classification ability of the instrument. Using the second trimester EPDS score, the AUC for minor to severe perinatal depressive symptomatology was 0.83 in the third trimester $(95 \% \mathrm{CI}=0.81-0.85)$ and 0.76 at 6 weeks postpartum $(95 \% \mathrm{CI}=0.72-0.80)$, while that for severe perinatal depressive symptomatology was 0.85 in the third trimester $(95 \% \mathrm{CI}=0.81-0.87)$ and 0.77 at 6 weeks postpartum $(95 \%$ $\mathrm{CI}=0.71-0.84)$ as shown in Figs. 2, 3, 4 and 5. These results suggest that the second trimester EPDS score, using different thresholds, has a good classification scheme and can distinguish women at risk for elevated EPDS scores and perinatal depressive symptoms in the third trimester and at 6 weeks postpartum.

\section{Discussion}

The aim of this study was to assess the pattern of perinatal depression over the second and third trimesters and at 6 weeks postpartum and determine the predictive validity of the second trimester EPDS score for future EPDS scores of perinatal depressive symptomatology. This is the first known population-based study to specifically evaluate these outcomes and examine the clinical utility of screening women using the EPDS in the second trimester among Hong Kong Chinese women.

Our study found that the mean EPDS score and proportion of women with depressive symptoms (EPDS> 9 and $>14$ ) were the highest in the second trimester, among the three time frames. This finding contradicts that of previous studies that the second trimester of pregnancy tends to be the calmest in terms of mood (Fraser et al. 2003). Possible explanations could be the majority of the women being undiagnosed and untreated for perinatal depression in the second trimester (Andersson et al. 2003) or the recurrence of depression in the second trimester because of discontinued antidepressant treatment (Cohen et al. 2006). It is noteworthy that the relapse rate is far from insignificant even among women who stay on medication (Lusskin et al. 2007). Several epidemiological studies have shown that depression is very common in women during the transition to parenthood in the second trimester (Alexander et al. 2001; Repokari et al. 2005), compared 
Table 3 Odd ratio $(95 \% \mathrm{CI})$ and adjusted odds ratio $(95 \% \mathrm{CI})$ of logistic regression of second trimester depressive symptoms associated with the third trimester and 6 weeks postpartum depressive symptoms in this study

\begin{tabular}{|c|c|c|c|c|c|c|c|c|c|}
\hline & \multirow[t]{2}{*}{ Number of cases $(n)$} & \multirow[t]{2}{*}{ OR } & \multicolumn{2}{|l|}{$95 \% \mathrm{CI}$} & \multirow[t]{2}{*}{ Sig. } & \multirow[t]{2}{*}{$\mathrm{aOR}^{\mathrm{a}}$} & \multicolumn{2}{|c|}{$95 \% \mathrm{CI}$} & \multirow[t]{2}{*}{ Sig. } \\
\hline & & & Lower & Upper & & & Lower & Upper & \\
\hline \multirow{5}{*}{$\begin{array}{l}\operatorname{EPDS}(9 / 10) \text { at } \\
\text { second trimester }\end{array}$} & \multicolumn{9}{|c|}{ EPDS $(9 / 10)$ at third trimester } \\
\hline & 1,569 & 9.94 & 7.78 & 12.69 & $<0.001$ & 9.74 & 7.59 & 12.51 & $<0.001$ \\
\hline & \multicolumn{9}{|c|}{ EPDS $(9 / 10)$ at 6 weeks postpartum } \\
\hline & 601 & 4.42 & 3.07 & 6.36 & $<0.001$ & 4.38 & 3.00 & 6.38 & $<0.001$ \\
\hline & \multicolumn{9}{|c|}{ EPDS $(14 / 15)$ at third trimester } \\
\hline \multirow{3}{*}{$\begin{array}{l}\text { EPDS }(14 / 15) \text { at } \\
\text { second trimester }\end{array}$} & 1,569 & 12.27 & 8.15 & 18.48 & $<0.001$ & 11.78 & 7.12 & 18.01 & $<0.001$ \\
\hline & \multicolumn{9}{|c|}{ EPDS $(14 / 15)$ at 6 weeks postpartum } \\
\hline & 601 & 6.90 & 3.66 & 12.99 & $<0.001$ & 7.15 & 3.63 & 14.09 & $<0.001$ \\
\hline
\end{tabular}

$O R$ odds ratio, $a O R$ adjusted odds ratio

${ }^{a}$ Adjusted for sociodemographic variables

to other phases (Eberhard-Gran et al. 2003). In addition, women may experience physical discomfort, such as headaches, which does not improve in the second trimester (Mohgini et al. 2004). These factors could explain our finding that the proportion of women experiencing perinatal depressive symptoms was greatest in the second trimester. This finding highlights the importance of close monitoring for perinatal depression in the second trimester.

Consistent with previous studies (Gorman et al. 2004; Dietz et al. 2007), we found that the proportion of women with severe depressive symptomatology (EPDS $>14)$ was slightly higher in the postpartum period $(8.7 \%)$ than the third trimester $(7.8 \%)$. This finding may reflect the added stress due to caring for a newborn (Dietz et al. 2007), the constant demands (van Bussel et al. 2009) of the infant, and

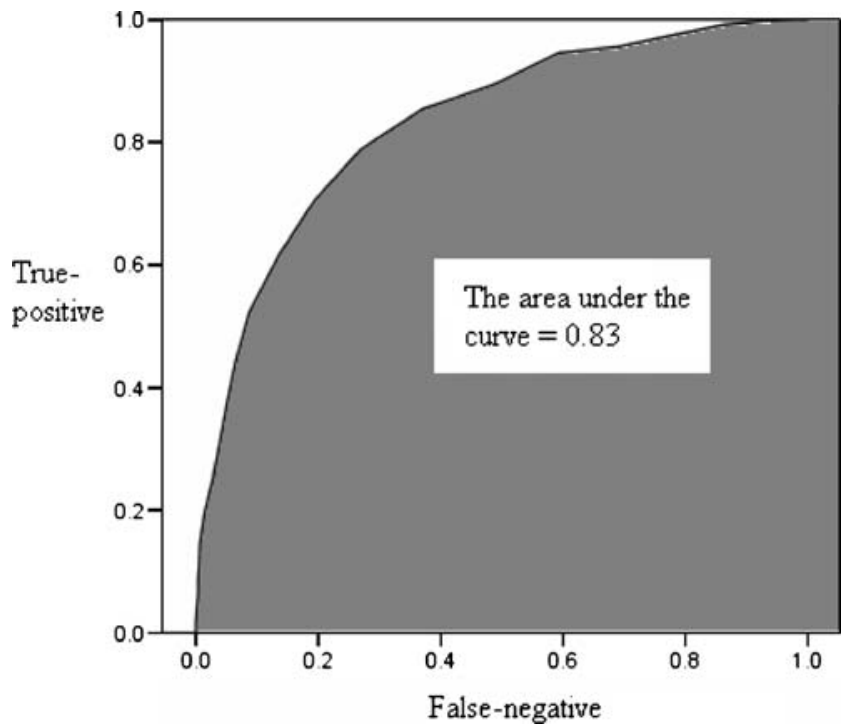

Fig. 2 The area under the curve for minor to severe perinatal depressive symptomatology in the third trimester by using the second trimester Edinburgh Postnatal Depression Scale score a limited maternity leave (approximately 6 weeks in Hong Kong) (Labour Department 2005). For some women, the events and circumstances of labor, delivery, and the postpartum period represent a unique and even traumatic stress that can precipitate perinatal depressive symptoms. Alternatively, returning to work outside the home appears to have a negative effect on women's emotional health. In Hong Kong, $75 \%$ of women aged $25-44$ years work full time (Hong Kong Census and Statistics Department 2009) with an average working week of at least 45 hours. With a large, densely populated (over 6.9 million people) urban environment and slowing economy, Hong Kong is a busy, work-intensive place. Most married couples are employed in the workforce, which may explain why over $50 \%$ of the mothers in the present study had full-time employment. The

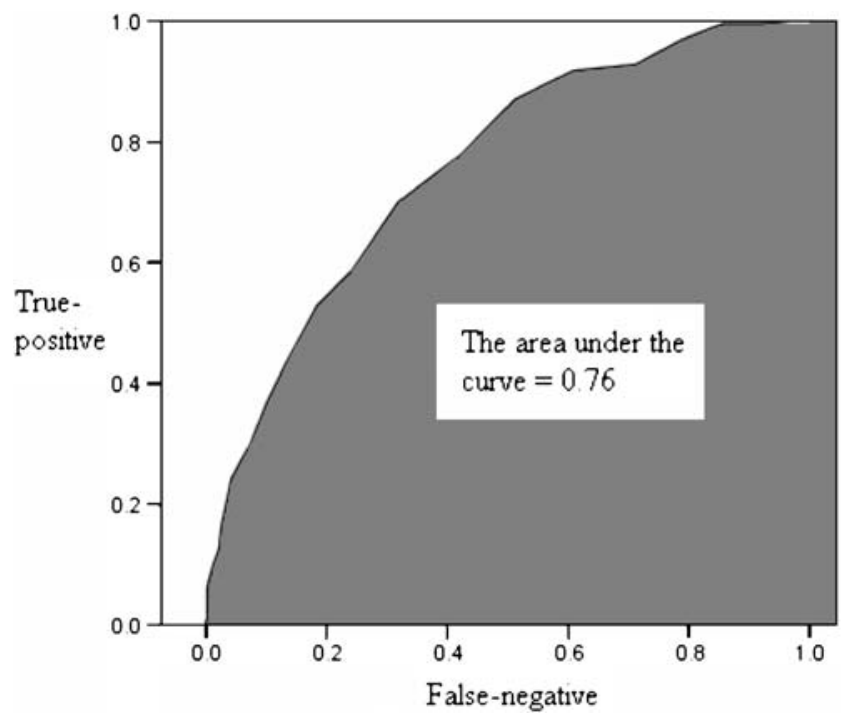

Fig. 3 The area under the curve for minor to severe perinatal depressive symptomatology at 6 weeks postpartum by using the second trimester Edinburgh Postnatal Depression Scale score 


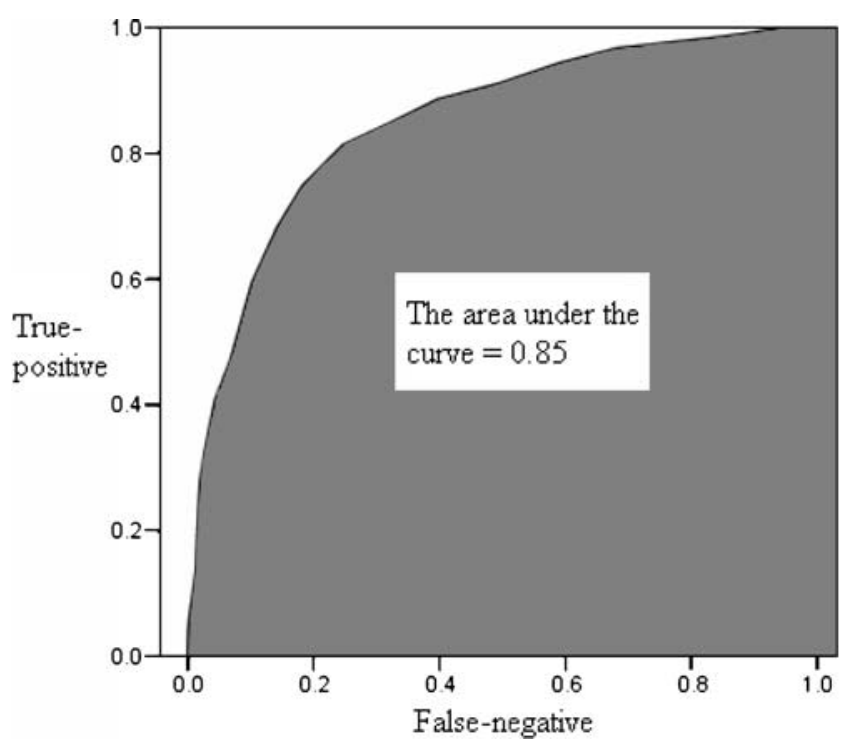

Fig. 4 The area under the curve for severe perinatal depressive symptomatology in third trimester by using the second trimester Edinburgh Postnatal Depression Scale score

maximum maternity leave available is 10 weeks, and a minimum of 2 weeks must be taken before the woman's expected date of confinement (Labour Department 2007). Early return to work has frequently been cited as a major reason for perinatal depression (Chan et al. 2002). However, because the number of women in our study with severe depressive symptomatology (EPDS $>14)$ was small $(n=53)$, no firm conclusion can be drawn about this finding.

This study clearly demonstrates a strong relationship among perinatal depressive symptoms in the second and third trimesters and at 6 weeks postpartum. In addition to the significant correlations among the EPDS scores for all time periods, using cut-offs of $9 / 10$ and $14 / 15$ for the second trimester EPDS score accurately classified the majority of women with elevated EPDS scores in the third trimester and at 6 weeks postpartum. These findings support the existence of a continuum in perinatal depressive symptoms from the second trimester to 6 weeks postpartum, and indicate that the EPDS has good predictive power in the second trimester to identify women at risk for elevated EPDS scores in the third trimester and at 6 weeks postpartum. Generally, diagnostic interviewing is impractical in busy clinical settings (Milgrom et al. 2008) because the formal diagnosis of depression requires significant diagnostic expertise and the investment of valuable clinical time. At present, no screening tool for the assessment of depression specific to pregnancy is available. A simple and reliable diagnostic screening instrument for the early detection of depression in pregnancy would enhance intervention strategies and benefit preventive efforts. The EPDS may be helpful in this regard (Cox and Holden
2003), as it is easy to administer and score and can be used as the basis to make referrals for further definitive diagnosis and treatment (Jevitt et al. 2006). In light of time constraints, limited staffing resources, minimal perinatal depression training in the majority of Hong Kong hospitals, and the tendency to emphasize physical rather mental health, the quality of care provided to women could be significantly enhanced by the use of the EPDS as an adjunct to routine clinical evaluation in the second trimester. As the prevention of perinatal depression is not feasible, early detection and treatment is the best approach (Dossett 2008).

Our data support the clinical utility of second trimester screening for perinatal depressive risk using the EPDS. The evaluation of women for depressive symptoms before delivery appears to yield an at-risk prevalence equivalent to that of postpartum screening, but discordant at-risk subsets exist between screening intervals. To the extent that second trimester screening identifies women among whom depression might not otherwise be detected, and because postpartum depression may have its origins before delivery (de Tychey et al. 2005; Stowe et al. 2005), routine second trimester screening could enhance detection overall and provide an important "head start" for intervention for perinatal depression. The extreme consequences of untreated and undetected perinatal depression (suicide and infanticide; Lusskin et al. 2007) have awakened public interest and engendered support for second trimester screening.

Although contributing to the literature, this study has several limitations. First, the EPDS has well-known limitations (Cox and Holden 2003), in that it can neither diagnose depression nor establish prevalence accurately. A

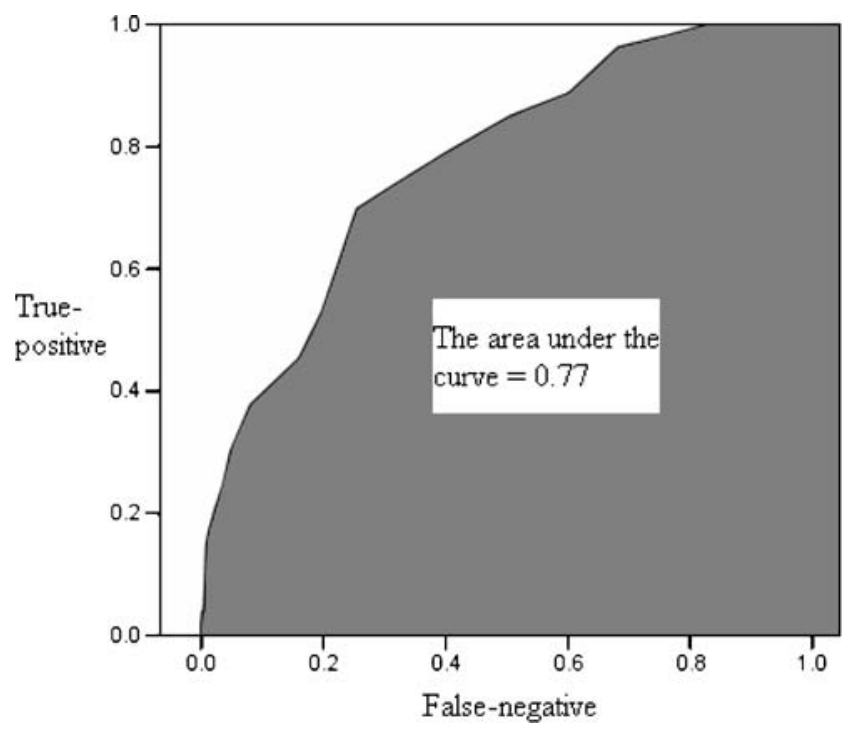

Fig. 5 The area under the curve for severe perinatal depressive symptomatology at 6 weeks postpartum by using the second trimester Edinburgh Postnatal Depression Scale score 
second limitation is that not all pregnant women participated and not all were actively followed-up in the postpartum period. Consequently, just over half of those who were followed-up responded in the third stage by mail survey, and the comparatively low return rate may have weakened the generalizability of the findings. Third, the participants were not asked about their use of medication for depression, and it is possible that some of them stopped mediation because of perceived or real contraindications with pregnancy. Fourthly, the participants were not asked about the psychotherapeutic interventions for depression therefore some of depressed women may have received the interventions. Finally, this study was designed to explore the influence of sociodemographic variables as potential confounders on perinatal depression. However, other important dimensions such as cultural or obstetric factors have not been considered.

\section{Conclusion}

Identifying perinatal depression is important for not only the mother but also the fetus and/or newborn. Case identification using the EPDS during the second trimester is appropriate and enables healthcare professionals to follow-up high-risk women and implement secondary preventive interventions or clinical interviews to establish a perinatal depression diagnosis.

Acknowledgments The authors would like to thank all of the women in the study for their participation.

\section{References}

Adouard F, Glangeaud-Freudenthal NM, Golse B (2005) Validation of the Edinburgh postnatal depression scale (EPDS) in a sample of women with high-risk pregnancies in France. Arch Womens Ment Health 8:89-95

Alder J, Fink N, Bitzer J, Hosli I, Holzgreve W (2007) Depression and anxiety during pregnancy: a risk factor for obstetric, fetal and neonatal outcome? A critical review of the literature. J Matern Fetal Neonatal Med 20:189-209

Alexander R, Feeney J, Hohaus L, Noller P (2001) Attachment style and coping resources as predictors of coping strategies in the transition to parenthood. Personal Relationships 8:137-152

Andersson L, Sundstrom-Poromaa I, Bixo M, Wulff M, Bondestam K, Astrom M (2003) Point prevalence of psychiatric disorders during the second trimester of pregnancy: a population-based study. Am J Obstet Gynecol 189:148-154

Andersson L, Sundstrom-Poromaa I, Wulff M, Astrom M, Bixo M (2004) Implications of antenatal depression and anxiety for obstetric outcome. Obstet Gynecol 104:467-476

Bennett HA, Einarson A, Taddio A, Koren G, Einarson TR (2004) Depression during pregnancy: overview of clinical factors. Clin Drug Investig 24:157-179
Bennett IM et al (2008) Efficiency of a Two-Item Pre-Screen to reduce the burden of depression screening in pregnancy and postpartum: an IMPLICIT Network study. Evid Based Clin Med 21:317-325. doi:10.3122/jabfm.2008.04.080048

Bowen A, Muhajarine N (2006) Antenatal depression. Canadian Nurse 102:26-30

Boyd RC, Pearson JL, Blehar MC (2002) Prevention and treatment of depression in pregnancy and the postpartum period: summary of a maternal depression roundtable: a US perspective. Arch Women Ment Health 4:79-82

Boyd RC, Le HN, Somberg R (2005) Review of screening instruments for postpartum depression. Arch Womens Ment Health 8:141-153

Buist A et al (2005) Recognition and management of perinatal depression in general practice - a survey of GPs and postnatal women. Aust Fam Physician 34:787-790

Buist A et al (2006) Acceptability of routine screening for perinatal depression. J Affect Disord 93:233-237

Campbell SB, Brownell CA, Hungerford A, Spieker SI, Mohan R, Blessing JS (2004) The course of maternal depressive symptoms and maternal sensitivity as predictors of attachment security at 36 months. Dev Psychopathol 16:231-252

Chan WCS, Levy V, Chung TKH, Lee DT (2002) A qualitative study of the experience of a group of Hong Kong Chinese women diagnosed with postnatal depression. J Adv Nurs 39:571-579

Chung TKH, Lau FTK, Yip ASK, Chiu HFK, Lee DTS (2001) Antepartum depressive symptomatology is associated with adverse obstetric and neonatal outcomes. Psychosom Med 63:830-834

Cohen J (1988) Statistical power analysis for the behavioral sciences 2nd edn. Erlbaum, Hillsdale

Cohen LS et al (2006) Relapse of major depression during pregnancy in women who maintain or discontinue antidepressant treatment. JAMA 296:499-170

Cox J, Holden J (2003) Perinatal mental health : a guide to the Edinburgh Postnatal Depression Scale (EPDS). Gaskell, London

Cox JL, Holden JM, Sagovsky R (1987) Detection of postnatal depression: development of the 10-item Edinburgh postnatal depression scale. Br J Psychiatry 150:782-786

de Tychey $\mathrm{C}$ et al (2005) Pre- and postnatal depression and coping: a comparative approach. J Affect Disord 85:323-326

Diaz MA, Le HN, Cooper BA, Munoz RF (2007) Interpersonal factors and perinatal depressive symptomatology in a low-income Latina sample. Cultur Divers Ethnic Minor Psychol 13:328-336

Dietz PM, Williams SB, Callaghan WM, Bachman DJ, Whitlock EP, Hornbrook MC (2007) Clinically identified maternal depression before, during, and after pregnancies ending in live births. Am J of Psychiatry 164:1515-1520

Dossett EC (2008) Perinatal depression. Obstet Gynecol Clin North Am 35:419-434

Eberhard-Gran M, Tambs K, Opjordsmoen S, Skrondal A, Eskild A (2003) A comparison of anxiety and depressive symptomatology in postpartum and non-postpartum women. Soc Psychiatry Psychiatr Epidemiol 38:551-556

Evans J, Heron J, Francomb H, Oke S, Golding J (2001) Cohort study of depressed mood during pregnancy and after childbirth. BMJ 323:257-260

Evans JR, Heron J, Patel RR, Wiles N (2007) Depressive symptoms in pregnancy and low birth weight at term: longitudinal study. Br J Psychiatry 191:84-85

Felice E, Saliba J, Grech V, Cox J (2006) Validation of the Maltese version of the Edinburgh Postnatal Depression Scale. Arch Womens Ment Health 9:75-80

Figueiredo B, Pacheco A, Costa R (2007) Depression during pregnancy and the postpartum period in adolescent and adult Portuguese mothers. Arch Womens Ment Health 10:103-109 
Fletcher RH, Fletcher SW (2005) Clinical epidemiology : the essentials, 4th edn. Lippincott Williams \& Wilkins, Baltimore

Flynn HA, Walton MA, Chermack ST, Cunningham RM, Marcus SM (2007) Brief detection and co-occurrence of violence, depression and alcohol risk in prenatal care settings. Arch Womens Ment Health 10:155-161

Fraser D, Cooper MA, Myles MF (2003) Myles textbook for midwives, 14th edn. Churchill Livingstone, Edinburgh

Gibson J, McKenzie-McHarg K, Shakespeare J, Price J, Gray R (2009) A systematic review of studies validating the Edinburgh Postnatal Depression Scale in antepartum and postpartum women. Acta Psychiatr Scand 119:350-364

Gorman LL et al (2004) Adaptation of the structured clinical interview for DSM-IV disorders for assessing depression in women during pregnancy and post-partum across countries and cultures. Br J Psychiatry - Supplementum 46:s17-23

Hong Kong Census and Statistics Department (2007) Hong Kong Statistics. In. Hong Kong Census and Statistics Department, The Government of the Hong Kong Special Administrative Region Hong Kong

Hong Kong Census and Statistics Department (2009) Hong Kong in figures: labour. In. Hong Kong Census and Statistics Department, Hong Kong. Available via http://www.censtatd.gov.hk/hong kong_statistics/statistical_tables/index_tc.jsp?htmlTableID= 008\&excelID $=\&$ chartID $=\&$ tableID $=016$. Accessed 3 Aug 2009

Hong Kong Housing Authority (2007) Housing in figures. In. Hong Kong Housing Authority and Housing Department., Hong Kong

Hospital Authority (2004) Hospital Authority statistical report: 2003 2004. In Hospital Authority, Hong Kong

Howell EA, Mora P, Leventhal H (2006) Correlates of early postpartum depressive symptoms. Matern Child Health J 10:149-157

Jekel JF, Jekel JF (2007) Epidemiology, biostatistics, and preventive medicine, 3rd edn. Saunders/Elsevier, Philadelphia

Jevitt C, Zapata L, Harrington M, Berry E (2006) Screening for perinatal depression with limited psychiatric resources. J Am Psychiatric Nurs Assoc 11:359-363

Jomeen J, Martin CR (2008) Reflections on the notion of post-natal depression following examination of the scoring pattern of women on the EPDS during pregnancy and in the post-natal period. J Psychiatr Ment Health Nurs 15:645-648

Kammerer M et al (2009) Symptoms associated with the DSM IV diagnosis of depression in pregnancy and post partum. Arch Womens Ment Health 12:135-141

Kim HG, Mandell M, Crandall C, Kuskowski MA, Dieperink B, Buchberger RL (2006) Antenatal psychiatric illness and adequacy of prenatal care in an ethnically diverse inner-city obstetric population. Arch Womens Ment Health 9:103-107

Kim JJ, Gordon TE, La Porte LM, Adams M, Kuendig JM, Silver RK (2008) The utility of maternal depression screening in the third trimester. Am J Obstet Gynecol 199:509 e501-509 e505

Labour Department (2005) A concise guide to the employment ordinance: maternity leave. In. Labour Department, the Government of Hong Kong Special Administrative Region, Hong Kong. Available via http://www.labout.gove.hk/text/eng/public/wcp/ EOConciseGuide/chapther6.htm. Accessed 3 Aug 2009

Labour Department (2007) Labour Legislation. In. Labour Department, The Government of Hong Kong Special Administrative Region, Hong Kong. Available via http://www.labour.gov.hk/ eng/faq/cap57h_whole.htm. Accessed 3 Aug 2009

Lee DT, Chung TK (2007) Postnatal depression: an update. Best Pract Res Clin Obstet Gynaecol 21:183-191

Lee DTS et al (1998) Detecting postnatal depression in Chinese women: validation of the Chinese version of the Edinburgh Postnatal Depression Scale. Br J Psychiatry 172:433-437
Lee DT, Chan SSM, Sahota DS, Yip ASK, Tsui M, Chung TKH (2004a) A prevalence study of antenatal depression among Chinese women. J Affect Disord 82:93-99

Lee DT, Yip AS, Leung TY, Chung TK (2004b) Ethnoepidemiology of postnatal depression: prospective multivariate study of sociocultural risk factors in a Chinese population in Hong Kong. Br J Psychiatry - Supplement 184:34-40

Leigh B, Milgrom J (2008) Risk factors for antenatal depression, postnatal depression and parenting stress. BMC Psychiatry 8:24

Limlomwongse N, Liabsuetrakul T (2006) Cohort study of depressive moods in Thai women during late pregnancy and 6 - 8 weeks of postpartum using the Edinburgh Postnatal Depression Scale (EPDS). Arch Womens Ment Health 10:103-109

Lusskin SI, Pundiak TM, Habib SM (2007) Perinatal depression: hiding in plain sight. Can J Psychiatry 52:479-488

Mattney S, Henshaw C, Elliott S, Barnett B (2006) Variability in use of cut-off scores and formats on the Edinburgh Postnatal Depression Scale-implications for clinical and research practice. Arch Womens Ment Health 9:309-315

Menard SW (2002) Longitudinal research, 2nd edn. Sage, Thousand Oaks

Milgrom J, Westley D, Gemmill AW (2004) The mediating role of maternal responsiveness in some longer-term effects of postnatal depression on infant development. Infant Behav Dev 27:443-454

Milgrom J et al (2008) Antenatal risk factors for postnatal depression: a large prospective study. J Affect Disord 108:147-157

Miller DC (1991) Handbook of research design and social measurement (5th edition). SAGE, Newbury Park

Mohgini F, Keller R, Deregibus A, Raviola F, Mongini T, Sancarlo M (2004) Personality trait, depression and migraine in women: a longitudinal study. Headache 44:631

Munro BH (2005) Statistical methods for health care research, 5th edn. Lippincott, Philadelphia

Murray D, Cox JL (1990) Screening for depression during pregnancy with Edinburgh depression scale (EPDS). J Reprod Infant Psychol 8:99-107

Nachmias CF, Nachmias D (2004) Research Methods in the Social Science. Worth, New York

Orr ST, Blazer DG, James SA, Reiter JP (2007) Depressive symptoms and indicators of maternal health status during pregnancy. $\mathrm{J}$ Womens Health 16:535-542

Repokari L et al (2005) The impact of successful assisted reproduction treatment on female and male mental during transition to parenthood: a prospective controlled study. Hum Reprod 20:3238-3247

Rubbin A, Babbie E (2001) Research methods for social work. Wadsworth/Thomas Learning, Australia

Sharp LK, Lipsky MS (2002) Screening for depression across the lifespan: a review of meaures for use in primary care settings. Am Fam Physician 66:1001-1008

Shih FJ (1996) Concepts related to Chinese patients perceptions of health, illness and person: issues of conceptual clarity. Accid Emerge Nurs 4:208-215

Singleton R, Straits BC (1999) Approaches to social research, 3rd edn. Oxford University Press, New York

Stowe ZN, Hostetter AL, Newport DJ (2005) The onset of postpartum depression: implications for clinical screening in obstetrical and primary care. Am J Obstet Gynecol 192:522-526

$\mathrm{Su} \mathrm{KP}$ et al (2007) Different cut-off points for different trimesters? The use of Edinburgh Postnatal Depression Scale and Beck Depression Inventory to screen for depression in pregnant Taiwanese women. Gen Hosp Psychiatry 29:436-441

Suri R, Altshuler L, Hellemann G, Burt VK, Aquino A, Mintz J (2007) Effects of antenatal depression and antidepressant treatment on gestational age at birth and risk of preterm birth. [see comment]. Am J Psychiatry 164:1206-1213 
Talge NM, Neal C, Glover V et al (2007) Antenatal maternal stress and long-term effects on child neurodevelopment: how and why? J Child Psychol Psychiatry 48:245-261

Thio IM, Oakley Browne MA, Coverdale JH, Argyle N (2006) Postnatal depressive symptoms go largely untreated: a probability study in urban New Zealand. Soc Psychiatry Psychiatr Epidemiol $41: 814-818$ van Bussel JCH, Spitz B, Demyttenaere K (2009) Depressive symptomatology in pregnant and postpartum women: an exploratory study of the role of maternal antenatal orientations. Arch Womens Ment Health 12:155-166

Wong Y, Guo X, Lau Y, Chan KS, Yin L, Chen J (2009) Psychometric evaluation of the Mainland Chinese version of Edinburg Postnatal Depression Scale. Int J Nurs Stud 46:813-823 